\title{
Pituitary Adenomas Associated with Intracranial Aneurysms - The Clinical Characteristics, Therapeutic Strategies, and Possible Effects of Vascular Remodeling Factors
}

\section{Yoshikazu Ogawa ( $\nabla$ yogawa@kohnan-sendai.or.jp )}

Kohnan Hospital https://orcid.org/0000-0002-6834-6468

Mika Watanabe

Tohoku University Hospital: Tohoku Daigaku Byoin

\section{Teiji Tominaga}

Tohoku University School of Medicine: Tohoku Daigaku Daigakuin Igakukei Kenkyuka Igakubu

\section{Research note}

Keywords: Association, Coexistence, Cerebral aneurysm, Pituitary adenoma, Vascular endothelial growth factor

Posted Date: October 9th, 2020

DOI: https://doi.org/10.21203/rs.3.rs-80983/v1

License: (c) (1) This work is licensed under a Creative Commons Attribution 4.0 International License.

Read Full License 


\section{Abstract}

Objective: Pituitary adenoma coexists with intracranial aneurysms in $2.3 \%$ to $3.6 \%$, and intracranial aneurysms is thought to be incidental. On the other hand higher age and cavernous sinus invasion are reported to increase the coexistence rate, so these two diseases may be related. Ten males and 14 females with coexistence of pituitary adenomas and intracranial aneurysms were retrospectively investigated among 923 patients (2.6\%). Patients were subdivided into two groups with/without direct attachment of cerebral aneurysms to the pituitary adenomas. The clinical characteristics, therapeutic strategies, and possible effects of vascular remodeling factors were investigated.

Results: Twelve patients had functioning pituitary adenomas, and cavernous sinus invasion was identified in 7 of 24 patients. Five of these 7 patients were treated with priority for the cerebral aneurysms until 2007, whereas 14 of 17 patients without involvement of the aneurysm tip in the tumor were treated with priority for pituitary adenomas in the later period. Among vascular remodeling factors strong expression of vascular endothelial growth factor (VEGF) was significantly associated with coexistence of pituitary adenoma and cerebral aneurysm $(p<0.05)$. So VEGF-induced arterial wall remodeling may be part of the mechanism of association between pituitary adenomas and cerebral aneurysms, suggesting possible causative mechanism.

\section{Introduction}

Pituitary adenoma associated with intracranial aneurysms requires complex and individual case discussions to establish the therapeutic strategies, and pituitary adenoma is reported to coexist with intracranial aneurysms in the anterior circulation of the circle of Willis in $2.3-3.6 \%$ of cases [1-4], but in the posterior circulation in much lower percentages [5-6]. Such rates of coexistence may be higher in acromegaly patients [6-8]. Therefore, the coexistence of pituitary adenomas and intracranial aneurysms is incidental. On the other hand, the coexistence rate is higher with age and cavernous sinus invasion, so the coexistence of these two diseases may be related [4,9-10]. Some statistical risk evaluations have examined coexistence, but no clinical or basic examinations have investigated the possible mechanism of association.

The present study investigated the clinical characteristics, therapeutic strategies and possible involvement of vascular remodeling factors within pituitary adenomas with tumor-related aneurysm formation.

\section{Materials And Methods}

This study retrospectively identified 10 males and 14 females aged from 37 to 75 years (mean 56.8 years) with pituitary adenomas coexisting with intracranial aneurysms among the 923 patients (2.6\%) initially treated by surgery with histological confirmation at the Department of Neurosurgery, Kohnan Hospital between April 2005 and October 2018. No patients had previously undergone treatment 
for the aneurysms and all aneurysms were un-ruptured. All patients were investigated preoperatively and just after the operation with coronal and sagittal T1-weighted, with and without contrast medium, and T2weighted magnetic resonance (MR) imaging, and MR angiography with the time of flight method (1.5 T system, Magnetom, Siemens, Erlangen, Germany and Signa Horizon, General Electric Medical Systems, Milwaukee, WI; 3.0 T system, Signa Excite HD 3T, General Electric Medical Systems). Therapeutic strategies were established through discussions between neurosurgeons and endovascular neurosurgeons specialized in cerebrovascular diseases to decide the therapeutic priority and method of treatment of the cerebral aneurysms for each individual case.

The surgical specimens were immediately fixed for histological and immunohistochemical examinations with $10 \%$ buffered formalin, embedded in paraffin, and serial sections were cut to $3 \mu \mathrm{m}$ thickness. Hematoxylin and eosin, and periodic acid-Schiff staining were performed in all cases. The avidin-biotinperoxidase complex method was applied for immunohistochemical staining using the following antibodies: polyclonal anti-growth hormone (GH) (GH, Dako, Glostrup, Denmark), polyclonal antiadrenocorticotropic hormone (ACTH) (ACTH, Dako), polyclonal anti-prolactin (PRL) (PRL, Dako), monoclonal anti-thyroid-stimulating hormone (SPM104, Lab Vision, Fremont, CA, 1:100), monoclonal anti-luteinizing hormone (LH) (LH01, Lab Vision, 1:500), monoclonal anti-follicle-stimulating hormone (FSH) (FSH03, Lab Vision, 1:500), and polyclonal anti-alpha-subunit hormone (CELL MARQUE, Rocklin, CA). Cell proliferation was assessed by immunohistochemical staining for Ki-67 (MIB-1, Dako, 1:100). If enough material was available, additional immunohistochemical staining was performed for mouse monoclonal anti-matrix metalloproteinase-9 (MMP-9) (15w2, Leica, Novocastra, UK, 1:80), goat polyclonal anti-hypoxia-inducible factor-1a (L2208, Santa Cruz Biotechnology, Inc., Santa Cruz, CA; 1:100), mouse monoclonal anti-vascular endothelial growth factor (VEGF) (JH121, Neo Markers, CA, 1:100), and mouse monoclonal anti-human cluster of differentiation 68 (CD68) (PGM1, Agilent, Dako, 1:200) as vascular remodeling factors.

Patients were subdivided into two groups with/without direct attachment of cerebral aneurysms to pituitary adenomas, and the immunohistochemical results were compared with the control group consisting of 21 pituitary adenoma patients without cerebral aneurysms. Statistical comparisons used Statmate 5 software (ATMS Co., Ltd., Tokyo, Japan), and $p$ values of less than 0.05 were regarded as significant. Overall study design was approved by the Ethical Committee of Kohnan Hospital 2019.

\section{Results}

Twelve patients with functioning pituitary adenomas suffered from hormonal excess symptoms, and the remaining 12 patients had non-functioning pituitary adenomas. Four patients with functioning adenomas had acromegaly with $\mathrm{GH}$ excess, and these patients accounted for $3.7 \%$ of 108 acromegaly patients treated within the same period. Most tumors were macroadenomas with average maximum diameters of $22.4 \mathrm{~mm}$, and only 3 tumors were microadenomas with maximum diameter of less than $10 \mathrm{~mm}$. Cavernous sinus invasion was identified in 7 patients and was not found in the remaining 17 patients. Direct attachment between the tumor and cerebral aneurysm was identified in 15 patients and not in the 
remaining 9 patients. All aneurysms were located in the anterior circulation of the circle of Willis except for 1 case of VA-PICA aneurysm (Table 1 ). 
Table 1

Clinical profiles of patients with pituitary adenomas associated with cerebral aneurysms

\begin{tabular}{|c|c|c|c|c|c|}
\hline Case & $\begin{array}{l}\text { Range of } \\
\text { Age }\end{array}$ & Histology & $\begin{array}{l}\text { Tumor size } \\
(\mathrm{mm})\end{array}$ & $\begin{array}{l}\text { Cavernous } \\
\text { invasion }\end{array}$ & Attachment \\
\hline 1 & $60-70 \mathrm{~s}$ & $\begin{array}{l}\text { non-functioning with } \\
\text { RCC }\end{array}$ & $30 \times 22 \times 19$ & $\mathrm{~N}$ & $\mathrm{~N}$ \\
\hline 2 & $40-50 s$ & mixed $\mathrm{GH}$ and $\mathrm{PRL}$ & $35 \times 25 \times 14$ & $\mathrm{~N}$ & $\mathrm{~N}$ \\
\hline 3 & $70-80 \mathrm{~s}$ & corticotroph & less than 2 & $\mathrm{~N}$ & $\mathrm{~N}$ \\
\hline 4 & $30-40 s$ & gonadotroph & $31 \times 29 \times 21$ & $\mathrm{~N}$ & $\mathrm{~N}$ \\
\hline 5 & $40-50 \mathrm{~s}$ & plurihormonal & $19 \times 19 \times 14$ & $\mathrm{~N}$ & $N$ \\
\hline 6 & $70-80 \mathrm{~s}$ & null cell & $29 \times 21 \times 21$ & left & $N$ \\
\hline 7 & $40-50 \mathrm{~s}$ & plurihormonal & $18 \times 19 \times 19$ & $\mathrm{~N}$ & $N$ \\
\hline 8 & $50-60 \mathrm{~s}$ & mixed $\mathrm{GH}$ and $\mathrm{PRL}$ & $21 \times 21 \times 11$ & $\mathrm{~N}$ & N \\
\hline 9 & $40-50 \mathrm{~s}$ & gonadotroph & $16 \times 21 \times 9$ & right & $\mathrm{N}$ \\
\hline 10 & $50-60 s$ & lactotroph & $15 \times 12 \times 10$ & left & Y \\
\hline 11 & $60-70 \mathrm{~s}$ & non-functioning & $12 \times 15 \times 10$ & $\mathrm{~N}$ & Y \\
\hline 12 & $50-60 \mathrm{~s}$ & plurihormonal & $28 \times 25 \times 23$ & right & Y \\
\hline 13 & $60-70 \mathrm{~s}$ & gonadotroph & $30 \times 25 \times 25$ & $\mathrm{~N}$ & $\mathrm{Y}$ \\
\hline 14 & $60-70 \mathrm{~s}$ & gonadotroph & $20 \times 20 \times 17$ & right & $\mathrm{Y}$ \\
\hline 15 & $60-70 \mathrm{~s}$ & lactotroph & $25 \times 31 \times 25$ & right & Y \\
\hline 16 & $60-70 \mathrm{~s}$ & gonadotroph & $21 \times 17 \times 15$ & $N$ & Y \\
\hline 17 & $60-70 \mathrm{~s}$ & gonadotroph & $21 \times 19 \times 19$ & $\mathrm{~N}$ & Y \\
\hline 18 & $40-50 \mathrm{~s}$ & corticotroph & less than 2 & $\mathrm{~N}$ & Y \\
\hline 19 & $40-50 \mathrm{~s}$ & gonadotroph & $25 \times 25 \times 18$ & $\mathrm{~N}$ & Y \\
\hline 20 & $70-80 \mathrm{~s}$ & mixed $\mathrm{GH}$ and $\mathrm{PRL}$ & $26 \times 21 \times 20$ & $\mathrm{~N}$ & $\mathrm{Y}$ \\
\hline 21 & $60-70 \mathrm{~s}$ & null cell & $17 \times 17 \times 12$ & $\mathrm{~N}$ & Y \\
\hline 22 & $60-70 \mathrm{~s}$ & mixed $\mathrm{GH}$ and $\mathrm{PRL}$ & $4 \times 7 \times 7$ & $\mathrm{~N}$ & $\mathrm{Y}$ \\
\hline 23 & $40-50 \mathrm{~s}$ & lactotroph & $41 \times 31 \times 43$ & right & $\mathrm{Y}$ \\
\hline 24 & $40-50 s$ & silent corticotroph & $31 \times 23 \times 20$ & $\mathrm{~N}$ & $\mathrm{Y}$ \\
\hline
\end{tabular}


Five of 7 patients with cavernous sinus invasion were treated with priority for the cerebral aneurysms until 2007. In contrast, 3 of 17 patients with the aneurysm tip involved in the tumor were treated with priority for the cerebral aneurysms, and 5 of 17 patients were treated with priority for the pituitary adenomas in the later period. The other 9 patients were treated only for pituitary adenomas with simple observation of the cerebral aneurysms. Patients with pituitary adenomas without direct attachment to cerebral aneurysms and with direct attachment to the aneurysm neck were treated with priority for the pituitary adenomas, and all patients were discharged without complications. Consequently, the emphasis of treatment priority had shifted from cerebral aneurysms to pituitary adenomas (Table 2). 
Table 2

Treatment strategy for associated aneurysms

\begin{tabular}{|c|c|c|c|c|}
\hline Case & $\begin{array}{l}\text { Aneurysm } \\
\text { location }\end{array}$ & $\begin{array}{l}\text { Aneurysm size } \\
(\mathrm{mm})\end{array}$ & Aneurysm treatment & Remarks \\
\hline 1 & Rt. M1 & 3 & observed & \\
\hline 2 & Lt. MCA & 12 & postoperative clipping & \\
\hline 3 & $\begin{array}{l}\text { Rt. A1-2, Lt. } \\
\text { IC-PC }\end{array}$ & $2.6,6.1$ & observed & \\
\hline 4 & Lt. IC-PC & 2 & observed & \\
\hline 5 & Lt. A2 & 2 & observed & \\
\hline 6 & Rt. VA-PICA & 2.5 & observed & \\
\hline 7 & Lt. IC-Acho & 4.8 & $\begin{array}{l}\text { postoperative } \\
\text { embolization }\end{array}$ & \\
\hline 8 & Rt. IC & 2 & observed & \\
\hline 9 & Lt. IC-Ophth & 2 & observed & \\
\hline 10 & Lt. IC-Ophth & 13 & preoperative clipping & \\
\hline 11 & Lt. IC-SHA & 7 & observed & \\
\hline 12 & Lt. IC-SHA & 8 & preoperative clipping & \\
\hline 13 & Lt. IC-SAH & 6.2 & preoperative embolization & \\
\hline 14 & Rt. IC-PC & 6 & $\begin{array}{l}\text { simultaneous clipping } \\
\text { and removal }\end{array}$ & \\
\hline 15 & Acom & 6 & preoperative clipping & destroyed skull base \\
\hline 16 & Acom & 3 & observed & \\
\hline 17 & $\begin{array}{l}\text { Acom, Rt. } \\
\text { MCA }\end{array}$ & 3,6 & postoperative clipping & \\
\hline 18 & Rt. IC-SAH & 12 & preoperative embolization & $\begin{array}{l}\text { wide attachment to } \\
\text { aneurysm tip }\end{array}$ \\
\hline 19 & Acom & 3 & observed & \\
\hline 20 & Acom & $5.6,2.8$ & observed & \\
\hline 21 & $\begin{array}{l}\text { Acom, distal } \\
\text { ACA }\end{array}$ & $6,3.3$ & $\begin{array}{l}\text { preoperative clipping, } \\
\text { wrapping }\end{array}$ & $\begin{array}{l}\text { involvement of aneurysm in } \\
\text { the tumor }\end{array}$ \\
\hline
\end{tabular}

MCA: middle cerebral artery, IC-PC: internal carotid-posterior communicating artery, VA-PICA: vertebralposteroinferior cerebellar artery, Acho: anterior choroidal artery, Ophth: ophthalmic artery, SHA:

superior hypophyseal artery, Acom: anterior communicating artery, ACA: anterior cerebral artery. 


\begin{tabular}{|lllll|}
\hline Case & $\begin{array}{l}\text { Aneurysm } \\
\text { location }\end{array}$ & $\begin{array}{l}\text { Aneurysm size } \\
(\mathbf{m m})\end{array}$ & Aneurysm treatment & Remarks \\
\hline 22 & Lt. IC-SAH & 5 & preoperative embolization & $\begin{array}{l}\text { involvement of aneurysm in } \\
\text { the tumor }\end{array}$ \\
\hline 23 & Acom & 6 & $\begin{array}{l}\text { postoperative } \\
\text { embolization } \\
\text { preoperative } \\
\text { pneumocephalus }\end{array}$ \\
\hline 24 & Acom & 5.8 & $\begin{array}{l}\text { postoperative } \\
\text { embolization }\end{array}$ & \\
\hline $\begin{array}{l}\text { MCA: middle cerebral artery, IC-PC: internal carotid-posterior communicating artery, VA-PICA: vertebral- } \\
\text { posteroinferior cerebellar artery, Acho: anterior choroidal artery, Ophth: ophthalmic artery, SHA: } \\
\text { superior hypophyseal artery, Acom: anterior communicating artery, ACA: anterior cerebral artery. }\end{array}$
\end{tabular}

Immunohistochemical examinations with vascular remodeling factors were investigated in 14 patients with direct attachment and without direct attachment, and the data were compared with a control group containing 21 patients without cerebral aneurysms. Expression of MMP-9 and CD 68 was stronger in the control group and weakest in the patients with direct attachment to cerebral aneurysms. No theoretical explanation can be proposed based on the coexistence of pituitary adenomas and cerebral aneurysms. In contrast, VEGF was only faintly expressed in the control group and patients without direct attachment, but stronger expression was identified in the patients with direct attachment (Table 3) (Fig. 1). Strong expression of VEGF was significantly associated with the coexistence of pituitary adenoma and cerebral aneurysm $(p<0.05)$. 
Table 3

Comparison of patients with/without cerebral aneurysms

\begin{tabular}{|c|c|c|c|}
\hline & $\begin{array}{l}\text { Patients with aneurysm } \\
(n=24)\end{array}$ & $\begin{array}{l}\text { Patients without } \\
\text { aneurysm }(n=21)\end{array}$ & Value \\
\hline Patient age (yrs) & 56.8 & 60.7 & $0.274^{\square}$ \\
\hline Sex (man / woman) & $10 / 14$ & $11 / 10$ & $0.472^{\square}$ \\
\hline $\begin{array}{l}\text { Histology (functioning / non- } \\
\text { functioning) }\end{array}$ & $12 / 12$ & $5 / 16$ & $0.070^{\square 0}$ \\
\hline Histology (acromegaly / others) & $4 / 20$ & $5 / 16$ & $0.550^{00}$ \\
\hline Preoperative tumor volume (ml) & 5.17 & 7.7 & $0.106^{\square}$ \\
\hline $\begin{array}{l}\text { Preoperative tumor maximum } \\
\text { diameter }(\mathrm{mm})\end{array}$ & 22.4 & 27.5 & $0.125^{\square}$ \\
\hline $\begin{array}{l}\text { Cavernous sinus invasion (yes / } \\
\text { no) }\end{array}$ & $7 / 17$ & $4 / 17$ & $0.431^{\square 0}$ \\
\hline $\begin{array}{l}\text { Attachment to adenoma (yes / } \\
\text { no) }\end{array}$ & $15 / 9$ & $0 / 21$ & $\begin{array}{l}<.001^{\mathrm{an}} \\
0\end{array}$ \\
\hline MMP-9 (non or faint / strong) & $10 / 4$ & $1 / 20$ & $\begin{array}{l}<.001^{\square 0} \\
0\end{array}$ \\
\hline HIF-1a (non or faint / strong) & $10 / 4$ & $16 / 5$ & $0.752^{\square}$ \\
\hline CD68 (low / high) & $12 / 2$ & $13 / 9$ & $0.091^{\square 0}$ \\
\hline VEGF (non or faint / strong) & $6 / 8$ & $17 / 4$ & $0.020^{\square 0}$ \\
\hline \multicolumn{4}{|c|}{$\begin{array}{l}\text { MMP-9: matrix metalloproteinase-9, HIF-1a: hypoxia-inducible factor-1a, CD68: cluster of } \\
\text { differentiation 68, VEGF: vascular endothelial growth factor. }\end{array}$} \\
\hline${ }^{\square}$ Mann-Whitney $U$ test, ${ }^{\square} \chi^{2}$ test. & & & \\
\hline
\end{tabular}

\section{Discussion}

Meta-analyses have shown that aneurysm has high risk of coexistence with autosomal familial polycystic kidney, familial history with cerebral aneurysm, and subarachnoidal hemorrhage, whereas lower risk is found for pituitary adenomas than overall brain tumors, and in the normal population without specific risk factors [11]. However the present study found stronger expression of vascular remodeling factor VEGF in patients with direct attachment of pituitary adenomas and cerebral aneurysms. Aneurysm formation is thought to be a result of complex interactions between biochemical and mechanical forces, and various vascular remodeling factors have been considered as causative of cerebral aneurysms and used in experimental aneurysm formation [12-17]. The present study may 
indicate possible VEGF-induced remodeling of the arterial walls. Therefore, preoperative screening examination for cerebral aneurysm using MR or computed tomography angiography should be performed in all the patients with attachment between pituitary adenomas and major cerebral arteries.

All the patients enrolled in this investigation had autocrine hormonal secretion and/or compression syndrome to neuronal structures by the tumors, whereas all the aneurysms were un-ruptured without compression syndrome. Clarification of the natural history of un-ruptured cerebral aneurysms [18] has changed the priority of treatment to pituitary adenomas as symptomatic lesions rather than asymptomatic un-ruptured aneurysms. Moreover, surgery is performed without discontinuation of antithrombotic therapy even in patients receiving anti-thrombotic agent in our institute [19], treatment strategy is not biased by the possibility of newly-introduced anti-platelets after intra-aneurysmal embolization. However, institutional and/or personal strategy is likely to be chosen for the patients receiving anti-thrombotic therapy, so individual case study discussion is still recommended.

\section{Conclusions}

Intracranial aneurysms were found to coexist in $2.6 \%$ of cases of surgically treated pituitary adenomas. Stronger expression of VEGF was shown in patients with pituitary adenomas with direct attachment to the aneurysms. VEGF-induced arterial wall remodeling may be part of the mechanism of cerebral aneurysm formation in case with coexisted pituitary adenomas.

\section{Limitations}

Finally there are some limitations in this study. This investigation analyzed a single institutional cohort containing a rather small number of patients, so prospective registration and accumulation of experience at multiple centers are essential to clarify the possible involvement of pituitary adenoma in tumor-related aneurysm formation.

\section{Abbreviations}

MR: magnetic imaging; GH: growth hormone; ACTH: adrenocorticotropic hormone; PRL: prolactin; LH: luteinizing hormone; FSH: follicle stimulating hormone; MMP-9: matrix metalloproteinase 9; VEGF: vascular endothelial growth factor

\section{Declarations}

\section{Ethics approval and consent to participate}

This is a retrospective and observational study, and no need to ethics approval and consent to participate are required. The therapeutic protocol was approved by the internal ethics committee of Kohnan Hospital 2019. 
Consent for publication

This is a retrospective and observational study.

Availability of data and material

All the data in this investigation were anonymous, and could be disclosed by the request from editor in chief.

\section{Competing interests}

The authors declare that they have no competing interests.

\section{Funding}

Not applicable

\section{Authors' contributions}

YO performed tumor removal all through the investigated period, and analyzed the patient data regarding the endocrinological outcome, and was a major contributor in writing the manuscript. MW performed all the pathological analyses in relation to this investigation. And TT gave an essential suggestion and supervised this manuscript. All authors read and approved the final manuscript.

\section{Acknowledgement}

Not applicable

\section{References}

1. Agarwal $\mathrm{H}$, Chugh $\mathrm{C}$, Singh S, Singh P: Neurosurgical image: giant pituitary adenoma and multiple aneurysms. Br J Neurosurg 2018, 33:312-314.

2. Akutsu N, Hosoda K, Ohta K, Tanaka H, Taniguchi M, Kohmura E: Subarachnoid hemorrhage due to rupture of an intracavernous carotid artery aneurysm coexisting with a prolactinoma under cabergoline treatment. J Neuro/ Surg Rep 2014, 75:e73-e76.

3. Berker M, Aghayey K, Saatci I, Palaoğlu S, Onerci M: Overview of vascular complications of pituitary surgery with special emphasis on unexpected abnormality. Pituitary 2010, 13:160-167.

4. Oh MC, Kim EH, Kim SH: Coexistence of intracranial aneurysm in $\mathbf{8 0 0}$ patients with surgically confirmed pituitary adenoma. J Neurosurg 2012, 116:942-947.

5. Habibi Z, Miri SM, Sheikhrezaei A: Pituitary macroadenoma coexistent with a posterior circulation aneurysm leading to subarachnoidal hemorrhage during transsphenoidal surgery. Turk Neurosurg 2015, 25:469-474. 
6. Manara R, Maffei P, Citton V, Rizzati S, Bommarito G, Ermani M, Albano I, Della Puppa A, Carollo C, Pavesi G, Scanarini M, Ceccato F, Sicolo N, Mantero F, Scaroni C, Martini C: Increased rate of intracranial saccular aneurysms in acromegaly: an MR angiography study and review of the literature. J Clin Endocrinol Metab 2011, 96:1292-1300.

7. Oshino S, Nishino A, Suzuki T, Arita H, Tateishi A, Matsumoto K, Shimokawa T, Kinoshita M, Yoshimine T, Saitoh Y: Prevalence of cerebral aneurysm in patients with acromegaly. Pituitary 2013, 16:195-201.

8. Xia X, Ramanathan M, Orr BA, Salmasi V, Salvatori R, Reh DD, Gallia GL: Expanded endonasal endoscopic approach for resection of a growth hormone-secreting pituitary macroadenoma coexistent with a cavernous carotid artery aneurysm. J Cin Neurosci 2012, 19:1437-1441.

9. Hanak BW, Zada G, Nayar VV, Thiex R, Du R, Day AL, Laws E: Cerebral aneurysms with intrasellar extension: a systemic review of clinical, anatomical, and treatment characteristics. J Neurosurg 2012, 116:164-178.

10. Raper DM, Ding D, Evans E, Starke RM, Crowley RW, Liu KC, Oldfield EH, Jane JA Jr.: Clinical features, management considerations and outcomes in case series of patients with parasellar intracranial aneurysms undergoing anterior skull base surgery. World Neurosurg 2017, 99:424-432.

11. Vlak MH, Algra A, Brandenburg R, Rinkel GJE: Prevalence of unruptured intracranial aneurysms, with emphasis on sex, age, comorbidity, country, and time period: a systemic review and meta-analysis. Lancet Neurol 2011, 10:626-636.

12. Chalouhi N, Ali MS, Jabbour PM, Tjoumakaris SI, Gonzaiez LF, Rosenwasser RH, Koch WJ, Dumont AS: Biology of intracranial aneurysms: role of inflammation. J Cereb Blood Flow Metab 2012, 32:1659-1676.

13. Frösen J, Cebral J, Robertson AM, Aoki T: Flow-induced, inflammation-mediated arterial wall remodeling in the formation and progression of intracranial aneurysms. Neurosurg Focus 2019, 47(1):E21.

14. Liu P, Shi Y, Fan Z, Zhou Y, Song Y, Liu Y, Yu G, An Q, Zhu W: Inflammatory smooth muscle cells induced endothelial cell alterations to influence cerebral aneurysm progression via regulation of integrin and VEGF expression. Cell Transplant 2019, 28:713-722.

15. Shimoda Y, Ogawa Y, Watanabe M, Tominaga T: Clinicopathological investigation of vascular endothelial growth factor and von Hippel-Lindau gene-related protein expression in immunohistochemically negative pituitary adenoma-possible involvement in tumor aggressiveness. Endocr Res 2013, 38:242-250.

16. Xu Z, Li H, Song J, Han B, Wang Z, Cao Y, Wang S, Zhao J: Meta-analysis of microarray-based expression profiles to identify differentially expressed genes in intracranial aneurysms. World Neurosurg 2017, 97:661-668.

17. Zhang X, Ares WJ, Taussky P, Ducruet AF, Grandhi R: Role of matrix metalloproteinases in the pathogenesis of intracranial aneurysms. Neurosurg Focus 2019, 47(1):E4. 
18. UCAS Japan Investigators, Morita A, Kirino T, Hashi K, Aoki N, Fukuhara S, Hashimoto N, Nakayama T, Sakai M, Teramoto A, Tominari S, Yoshimoto $T$ : The natural course of unruptured cerebral aneurysms in a Japanese cohort. N Engl J Med 2012, 366:2474-2482.

19. Ogawa $Y$, Tominaga $T$ : Sellar and parasellar tumor removal without discontinuing antithrombotic therapy. J Neurosurg 2015,123:794-798. 